\title{
Moral Hazard and Non-Exclusive Contracts*
}

\author{
Alberto Bisin ${ }^{\dagger}$ \\ Danilo Guaitoli \\ New York University \\ Universitat Pompeu Fabra \\ and CEPR
}

June 1998

*This is a much revised version of early work contained in a Delta-Crest Working Paper with the title 'Financial Markets, Asymmetric Information and Growth', and in Bisin-Guaitoli (1995). Thanks to Richard Arnott, Gary Becker, Peter Diamond, José Scheinkman, Robert Townsend as well as Daron Acemoglu, Alberto Bennardo, Pierre-André Chiappori, Roger Guesnerie, Jim Peck, and seminar audiences at many universities. Financial support from the HCM program of the EEC, the Spanish DGICYT program and the C.V. Starr Center for Applied Economics is gratefully acknowledged.

†Dept. of Economics, New York University, 269 Mercer Street, 10003 New York, NY. E-mail: bisina@fasecon.econ.nyu.edu

$\ddagger$ Dept. of Economics, Universitat Pompeu Fabra, Trias Fargas 25-27, 08005 Barcelona, Spain. E-mail: guaitoli@upf.es 


\title{
Moral Hazard and Non-Exclusive Contracts
}

\begin{abstract}
This paper studies equilibria for economies characterized by moral hazard (hidden action), in which the set of contracts marketed in equilibrium is determined by the interaction of financial intermediaries.

The crucial aspect of the environment that we study is that intermediaries are restricted to trade non-exclusive contracts: the agents' contractual relationships with competing intermediaries cannot be monitored (or are not contractible upon).

We fully characterize equilibrium allocations and contracts. In this set-up equilibrium allocations are clearly incentive constrained inefficient. A robust property of equilibria with non-exclusivity is that the contracts issued in equilibrium do not implement the optimal action. Moreover we prove that, whenever equilibrium contracts do implement the optimal action, intermediaries make positive profits and equilibrium allocations are third best inefficient (where the definition of third best efficiency accounts for constraints which capture the non-exclusivity of contracts).
\end{abstract}

Keywords: asymmetric information, exclusivity, efficiency. JEL: D82, D61, G20. 


\section{Introduction}

Models of contracts with asymmetric information are usually models of exclusive contractual relationships. In other words, it is assumed that a party in a contract can enforceably restrict the other party's participation to contractual relationships with other agents ${ }^{1}$. As a consequence agents cannot undo the incentive effects of one contract by engaging in additional contractual relationships with other agents or institutions. In terms of informational requirements, exclusive contracts effectively require that the institutions which design the contracts are able to perfectly monitor agents' trading with other institutions. Also, courts can enforce exclusive contracts only if agents' trades are observable and verifiable, which requires a rich institutional setting to allow courts to centralize information about trades.

Enforceability of exclusive contracts is a strong assumption, and while it is a very useful benchmark ${ }^{2}$, there are many interesting economic environments in which exclusive contracts are not easily enforceable.

For instance, in economies with relevant interactions of formal and informal sectors, the informal financial markets (often represented by institutions like family links and private money-lenders) are not easily monitored by, and do not easily monitor, formal markets like banks and government institutions. That informational constraints severely limit the enforceability of exclusive credit relationships in developing economies has been documented for instance by Aleem (1990) for Pakistan, and Siamwalla et al. (1990) for Thailand. Relatedly, the success of various microfinance programs like the Grameen Bank in Bangladesh (cf. e.g. Morduch (1997)) is often explained in terms of their ability to partially relax the informational constraints on exclusivity by means of extensive monitoring. ${ }^{3}$

Also, 'monitoring technologies' are often quite costly or are regulated in insurance and credit markets, and as a consequence exclusive contracts are not enforced. For instance, small business in the U.S. often have multiple credit sources (PetersenRajan (1994)); agents often hold several credit cards (Bizer-De Marzo (1992)); debt covenants in financial contracts rarely include exclusivity clauses (Smith-Warner (1979)); the regulatory limits on enforcement of contracts with no collateral might

\footnotetext{
${ }^{1}$ Cf. e.g. the survey of contract theory by Hart-Holmstrom (1987). Even general equilibrium analysis of economies with asymmetric information rely heavily on exclusivity assumptions: cf. e.g. Prescott-Townsend (1984), Townsend (1987) for theoretical foundations, and Townsend (1994), Atkinson-Lucas (1992) for more applied analysis.

${ }^{2}$ And a natural one e.g. in markets like the automobile insurance market, where the insurers can effectively monitor the contractual relationships of the insuree with other insurance companies.

${ }^{3}$ Cf. e.g. Mc Kinnon (1973), Shaw (1973), and more recently Bencivenga-Smith (1991), Greenwood-Jovanovic (1990), Hoff-Stiglitz (1997) for theoretical analysis of the interaction of formal and informal financial markets in developing economies.
} 
explain the thinness of the commercial credit markets in Italy ${ }^{4}$ (Guiso-JappelliTerlizzese (1991).

Finally, economies of scope substantially limit the design of exclusive contracts. For instance government agencies which provide social security or unemployment insurance programs cannot easily monitor private savings without also trading a rich array of financial instruments. ${ }^{5}$ Similarly, car insurance companies cannot monitor gasoline purchases by insurees without also setting up gas stations; firms often cannot monitor either managers' wealth, when designing their compensation schemes,

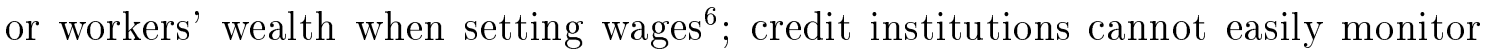
trade credit; and so on.

In this paper we depart from the analysis of exclusive contractual relationships, and study equilibria of economies with asymmetric information in which contracts are restricted to be non-exclusive. This is done in a simple general equilibrium environment. We define equilibrium with non-exclusivity as requiring i) agents to take the set of contracts available for trade in financial markets as well as prices as given, and ii) financial intermediaries to choose strategically the set of contracts they issue by rationally anticipating the agents' equilibrium choices for any possible set of contracts.

We concentrate on economies with moral hazard in the form of hidden action. These economies have been used to study credit markets as well as insurance markets, and many other contractual relationships. Agents choose a costly effort, e.g. to put in an investment activity. Effort is agents' private information, and affects the probability distribution of the investment's outcome. Financial intermediaries issue contracts to insure agents on their outcome realization without being able to condition on the effort. We analyze the simplest case in which effort is discrete ('high' or 'low'), although the results can qualitatively be extended to the continuous effort case.

For this class of economies we are able to characterize equilibria with nonexclusivity. We show that in equilibrium the 'low' effort might be implemented even if both the incentive constrained optimal contract and autarchy (i.e. when no contract is traded) can implement the 'high' effort. These equilibria occur because of the intermediaries' incentive to fully insure agents conditionally on their undertaking the 'low' effort whenever other intermediaries provide insurance conditionally on their undertaking the 'high' effort (i.e. at more favorable terms for the agents). As a consequence 'high' effort can only be sustained (if at all) as an equilibrium when

\footnotetext{
${ }^{4}$ Cf. e.g. Bertini (1967) for an institutional analysis of the regulation of credit contracts with no collateral in Italy.

${ }^{5}$ Cf. Diamond-Mirlees (1996), Kotlikoff-Spivak (1981).

${ }^{6}$ This might partially explain why managers' wages are relatively flat with respect to their firm's market value; cf. Gibbons (1997).
} 
contracts can be designed to prevent entry of other contracts which adversely affect incentives for the incumbents. Analyzing the conditions under which the 'high' effort is implemented and the kind of contracts which sustain these equilibria, we show that they generally involve intermediaries making positive profits, and require issuing 'latent' contracts, i.e. contracts which are not traded in equilibrium, but act as barriers to entry when marketed.

'Latent' contracts, while serving the purpose of restricting entry of contracts with negative incentive effects on the incumbent contracts, also inevitably act to guarantee rents in equilibrium to the intermediaries issuing the incumbent contracts which support the agents' 'high' effort. In general we can then prove that, because of the rents of intermediaries, equilibrium allocations which support agents' high effort are third best inefficient. In other words, if a planner could operate transfers across agents (transfers which can of course only be contingent on observables) before markets open, then the tranfer could be chosen so that in equilibrium all agents would be better off.

\section{$1.1 \quad$ Related Literature}

The analysis of moral hazard economies characterized by non-exclusivity has been pioneered by R. Arnott and J. Stiglitz in a sequence of unpublished papers in the early 80's (their work is now collected in Arnott-Stiglitz (1993)) and by the enlightening comments on their work by Hellwig (1983). ${ }^{7}$ Our paper is mostly related to this line of work. We study basically the same class of economies as Arnott-Stiglitz (1993) and Hellwig (1983), but we allow for a larger strategy space of intermediaries (containing 'negative insurance' contracts; i.e. insurance contracts which pay in the high endowment state). It turns out that this generalization simplifies substantially the analysis and the classification of equilibria with non-exclusivity. In particular this allows us to study in detail the welfare properties of equilibrium allocations.

Kahn-Mookherjee (1997) also analyzes efficiency of equilibria with non-exclusivity in a hidden action environment. The structure of the game intermediaries and agents play in their model is quite different though from ours: e.g. in their model agents design their own contracts (intermediaries just either accept or reject); also agents make contractual decisions sequentially; and their contractual portfolios are observable, even if not contractible upon. It turns out then that equilibrium allocations and welfare properties for our economy are very different from those of the KahnMookherjee (1997) economy. In particular, in our set-up allocations are robustly

\footnotetext{
${ }^{7}$ But cf. also Bizer-de Marzo (1992), Helpman-Laffont (1975), Jaynes (1978), Pauly (1968). The analysis of equilibria with non-exclusivity is also related to the analysis of 'common agency' (i.e. agency with many principals) in the contract theory literature; cf. e.g. Bernheim-Whinston (1986).
} 
third best inefficient.

Finally, Helpman-Laffont (1975) (cf. also Bisin-Gottardi (1997)) study competitive equilibria in economies with hidden action. In their set-up linearity of prices captures a strong form of non-exclusivity: each intermediary has no control over agents' trades, not even over trades of his own contracts. In the set-up of the present paper instead intermediaries control agents' trades in the contracts they themselves issue. ${ }^{8}$

\section{The Economy}

The economy lasts two periods, $t \in\{0,1\}$. It is populated by a continuum of ex-ante identical agents, indexed by $i \in I$ with total measure 1 , and by a large finite number of financial intermediaries, indexed by $h \in H$. Agents choose in $t=0$ an effort which is private information, and which can take two values, $e \in\{a, b\}$. Agents are risk averse; they have preferences which value consumption in period 1 only, and effort $e: u(c)-v(e)$. We assume that $u: \Re_{+} \rightarrow \Re$ is twice differentiable, strictly increasing, strongly concave and $\lim _{c \rightarrow 0} u(c)=-\infty$. We also assume without loss of generality that $v(a)>v(b)$.

Agent $i$ 's endowment at $t=1$ is a random variable $w^{i}$ which is i.i.d. across agents $i \in I$, and whose realization is publicly observable (from now on drop the apex $i$ to save on notation). The random variable $w$ takes values $w_{H}, w_{L}$, with $w_{H}>w_{L}$.

Effort affects the probability distribution of the endowments: let $\pi_{a}$ (resp. $\pi_{b}$ ) denote the probability of endowment $w_{H}$ given effort $a$ (resp. $b$ ). Assume $\pi_{a}>\pi_{b}$. The reader will have noticed that $H$ (resp. a) takes the interpretation of the 'high endowment state' (resp. 'high effort').

Remark 1 As standard in moral hazard environments, we use the properties of large economies. In particular, the Law of Large Numbers allows us to identify $\pi_{e}$ with the fraction of agents which observe the realization $w_{H}$ when producing effort $e$ (cf. Al-Najjar (1995)).

Prior to the beginning of time, intermediaries strategically design contracts. Each intermediary $h$ can design and issue $J^{h}$ contracts, and $J$ is the set of contracts issued overall. A contract prescribes a set of transfers from the intermediary to the buyer (possibly negative) conditionally on publicly observable variables. Formally, a contract $j \in J$ is a couple $d^{j}=\left(d_{H}^{j}, d_{L}^{j}\right)$ representing the payoff respectively in state $H$ and $L$. Note that contracts only pay off in period 1 (since agents only consume in period 1). Intermediaries can also make a contract divisible allowing agents to buy

\footnotetext{
${ }^{8}$ As a consequence, while a third best inefficiency result for competitive equilibria with linear prices is proved by Bisin-Gottardi (1997), the result in this paper is much stronger.
} 
fractions $\lambda_{j} \in[0,1]$. So a complete specification of contract $j$ would be $\hat{d}^{j}=\left\{d^{j}, \Lambda_{j}\right\}$, where $\Lambda_{j}$ (the set of admissible $\lambda_{j}$ ) is either $\{0,1\}$ (indivisible) or $[0,1]$ (divisible). As it turns out that only one type of contracts will be made divisible in equilibrium (the 'latent contracts' in the high effort equilibrium), to save on notation in the characterization we will often refer to a contract only by its transfers $d^{j}$, intended to be indivisible unless specified otherwise. Let $\hat{d}^{h}=\left(\hat{d}^{j}\right)_{j=1}^{J^{h}}$ denote the set of contracts issued by intermediary $h$. Intermediaries maximize profits. ${ }^{9}$

\subsection{Equilibrium and Optimality}

We can now start constructing the equilibrium definition we shall use in this paper: equilibrium with non-exclusivity. Given the set of contracts issued by intermediaries, agents choose which contracts to buy. This determines their consumption allocations. Agents also choose effort. Anticipating the choices of agents, as a function of the set of contracts they are allowed to trade, intermediaries strategically choose which contracts they issue, to maximize profits. We will restrict for the sake of notation the analysis to symmetric equilibria (in which all agents behave identically). ${ }^{10}$

The problem solved by agents can be formally described as follows. Each agent chooses effort $e \in\{a, b\}$, portfolio choices $\lambda=\left\{\lambda_{j} \in \Lambda_{j}\right\}_{j \in J}$, and consumption $c=\left(c_{H}, c_{L}\right)$, to maximize:

$$
E[u(c)-v(e) \mid e]
$$

subject to

$$
c=w+\sum_{j \in J} \lambda_{j} d^{j}
$$

The term $E[. \mid e]$ denotes the expectation over $w$ given $e \in\{a, b\}$. Note that if $\Lambda_{j}=\{0,1\}$ agents can either buy or not buy contract $j$; they cannot buy just a fraction, although they can buy multiples if the same contract is issued by more than one intermediary. This reflects our modelling of non-exclusivity as a form of inability of each intermediary to observe agents' trades with other intermediaries.

The problem solved by intermediaries can be described as follows. Intermediary

\footnotetext{
${ }^{9}$ More general hidden action economies share the same properties. In particular the results can be extended to economies with continuous effort choice and any finite number of states of uncertainty.

${ }^{10}$ Symmetric equilibria might not in general exist in this class of economies due to non-convexities in the agents' choice set.
} 
$h \in H$ chooses $\hat{d}^{h}=\left(\hat{d}^{j}\right)_{j=1}^{J^{h}}$ to minimize: ${ }^{11}$

$$
\sum_{j \in J^{h}} E\left[d^{j} \mid e\right] \lambda_{j}
$$

subject to:

$$
e, \lambda \text { solve (1)-(2), }\left(\hat{d}^{h^{\prime}}\right)_{h^{\prime} \neq h} \text { given }
$$

Note that intermediaries effectively play a simultaneous game by choosing the structure of contracts they trade.

Definition 1 (Equilibrium) An equilibrium with non-exclusivity is an array

$$
<e, \lambda, c,\left(\hat{d}^{h}\right)_{h \in H}>
$$

such that

i) $<e, \lambda, c>$ maximize (1) subject to (2) given $\hat{d}=\left(\hat{d}^{h}\right)_{h \in H}$;

ii) $\hat{d}^{h}$ maximizes (3) subject to (4), given $\left(\hat{d}^{h^{\prime}}\right)_{h^{\prime} \neq h}$ for any $h \in H$.

This definition of equilibrium (with a strategic component in the intermediaries' choices) has been used in different contexts by Rotschild-Stiglitz (1976), ArnottStiglitz (1993) and many others (cf. also Mas Colell (1982)).

We can now introduce the definitions of Pareto optimum, incentive constrained optimum, and third best optimum.

At the Pareto optimum a planner chooses agents' effort and the set of contracts to be traded to maximize agents' utility subject to the definition of consumption (equation (2)) and the zero profits constraint on intermediaries (equation (5)). ${ }^{12}$

Definition 2 (Pareto Optimum) The Pareto optimum, or first best, is an array

$$
<e, \lambda, c,\left(\hat{d}^{h}\right)_{h \in H}>
$$

which maximizes (1) subject to equation (2) and

$$
\sum_{j \in J^{h}} E\left[d_{t}^{j} \mid e\right] \lambda_{j}=0
$$

\footnotetext{
${ }^{11}$ We implicitely assume that intermediaries have large enough endowments to avoid bankruptcy issues. Note also that they do not need to be risk averse: profits in fact are deterministic because of the Law of Large Numbers; the conditional expectation in equation (3) should not mislead the reader.

${ }^{12}$ Both here and in the definition of Incentive Constrained Optimum, next, we directly impose zero profits rather than non-negative profits. Bennardo-Chiappori (1998) prove that this is (only) justified in economies, like ours, in which effort enters separably in agents' preferences. We will show instead that at the Third Best Optimum profits might turn out to be positive; cf. the proof of Proposition 6.
} 
At the incentive constrained optimum a planner chooses agents' effort and the set of contracts to be traded to maximize agents' utility subject to the definition of consumption, the zero profits constraint on intermediaries (equation (5)), and the incentive compatibility constraint (equation (6)).

Definition 3 (Incentive Constrained Optimum) The incentive constrained optimum is an array

$$
<e, \lambda, c,\left(\hat{d}^{h}\right)_{h \in H}>
$$

which maximizes (1) subject to: equation (2), equation (5) and

$$
\lambda, \text { e solve (1)-(2) given }(\hat{d})_{h \in H}
$$

Remark 2 It is easy to show that by imposing zero profits on intermediaries, we essentially pick the particular point on the incentive constrained frontier which would be decentralized by competitive equilibria if exclusive contracts were allowed; see Prescott-Townsend (1984). In this case in fact

i) competition in the contract design implies that only one type of contract is issued at the equilibrium: $\hat{d}_{j}=\hat{d}_{j^{\prime}}, \forall j \in J$; while

ii) price competition drives profits to zero for all $j \in J: E\left[d^{j} \mid e\right] \lambda_{j}=0$

Since non-exclusivity introduces restrictions in the intermediaries' problem (in addition to incentive compatibility), it is natural and interesting to define and characterize a 'third best' optimum in which the planner also faces these restrictions. In particular, following e.g. Guesnerie (1995), we assume that the planner chooses transfers, $\tau=\left(\tau_{h}, \tau_{L}\right)$, prior to markets opening but anticipating the equilibrium with non-exclusivity which will occur from endowments $w+\tau$. Transfers are naturally required to be 'self-sustainable', i.e. to have a zero (or negative) expected value (equation $(7)$ ).

Definition 4 (Third Best Optimum) The third best optimum is an array

$$
<e, \lambda, c,\left(\hat{d}^{h}\right)_{h \in H}, \tau>
$$

which maximizes (1) subject to:

$e, \lambda, c,\left(\hat{d}^{h}\right)_{h \in H}$ are an equilibrium with non-exclusivity for an economy with endowments $w+\tau$, and

$$
E[\tau \mid e] \leq 0
$$

\section{Characterization}

We are now ready for the characterization of equilibria with non-exclusivity and the inefficiencies associated with this equilibrium concept. ${ }^{13}$

\footnotetext{
${ }^{13}$ All proofs are collected in the Appendix.
} 
The following proposition shows that, except in the trivial case in which it coincides with the Pareto optimum, the incentive constrained optimum cannot be decentralized by an equilibrium with non-exclusivity.

Proposition 1 Suppose $d^{i c}$ is the incentive constrained optimal contract. Suppose also that the incentive constrained optimum does not coincide with the Pareto optimum. Then there exists a contract $d^{j^{\prime}}=\left\{d_{H}^{j^{\prime}}, d_{L}^{j^{\prime}}\right\}$ such that, if $d^{j}=d^{i c}$, and both $d^{j}$ and $d^{j^{\prime}}$ are issued in equilibrium, $E\left[d^{j} \mid e\right] \lambda_{j}>0$ and $E\left[d^{j^{\prime}} \mid e\right] \lambda_{j^{\prime}}<0$.

Figure 1 illustrates graphically the proof of this proposition. $w$ is the endowment point; $\left(1-\pi_{e}\right) / \pi_{e}$ is the fair price (the slope of the zero profit line) conditional on effort $e \in\{a, b\} ; u^{e}$ is the indifference curve with effort $e$, drawn so that $u^{a}$ and $u^{b}$ have the same expected utility; $c^{i c}$ is the incentive constrained optimum allocation. Since $\left(1-\pi_{b}\right) / \pi_{b}>\left(1-\pi_{a}\right) / \pi_{a}$, the marginal rate of substitution at any $c_{H}, c_{L}$ is higher on $u^{b}$ than on $u^{a}$. Any point in the shaded area can be reached from $c^{i c}$ with a contract making positive profits and is preferred by agents to $c^{i c}$. This proves that $c^{i c}$ cannot be an equilibrium with non-exclusivity.

$$
<\text { Figure } 1>
$$

Leaving the simple analytic details of the proof to the reader, it is interesting to characterize the contract $d^{j^{\prime}}$ which makes positive profits when coupled with the incentive constrained optimal contract. Since agents when buying only $\left\{d^{j}\right\}$ in equilibrium are indifferent between $e=a$ and $e=b$ (Lemma 1 in the Appendix), there exists a contract $\left\{d^{j^{\prime}}\right\}$ with the following properties:

- $d_{L}^{j^{\prime}}>0, d_{H}^{j^{\prime}}<0$, and $\pi_{b} d_{H}^{j^{\prime}}+\left(1-\pi_{b}\right) d_{L}^{j^{\prime}}=-\epsilon$ (small enough),

- agents prefer $d^{j}+d^{j^{\prime}}$ to $d^{j}$.

The first property states that contract $d^{j^{\prime}}$ offers positive insurance and makes profits $\epsilon$ (i.e. the price of the insurance is less than fair for the agents). The second property guarantees that agents nonetheless prefer to buy the combination of contracts $d^{j}$ and $d^{j^{\prime}}$ rather than the incentive constrained optimal contract $d^{j}$ by itself.

As a consequence, if both $\tilde{d}=\left\{d^{j}, d^{j^{\prime}}\right\}$ are issued, agents choose effort $e=b$, the intermediary issuing $d^{j}$ makes negative profits, while the one issuing $d^{j^{\prime}}$ makes positive profits.

We are now able to provide a characterization of equilibria with non-exclusivity. We will first derive conditions under which equilibria implement the low effort (Proposition 2). We will then show that whenever equilibria with non-exclusivity 
implement the high effort, then the set of contracts issued in equilibrium has a particular form: contracts are issued which operate as a barrier to entry (Proposition 3 ) and generally guarantee positive profits to intermediaries (since these contracts turn out not to be traded in equilibrium they are called latent contracts, following Hellwig's terminology).

The special case in which agents have logarithmic preferences can be worked out in closed form to provide examples of equilibria both with low and high effort, for different parametrizations of the cost of effort $v(e)$ (Proposition 4). In particular, we can show that equilibria with low effort arise robustly also for economies in which, if agents traded the incentive constrained optimal contract or if they traded no contracts at all, they would deliver the high effort (Proposition 5).

Proposition 2 Define $K=v(a)-v(b)$. If

$$
\pi_{a} u\left(c_{H}\right)+\left(1-\pi_{a}\right) u\left(c_{L}\right)-u\left(\pi_{b} c_{H}+\left(1-\pi_{b}\right) c_{L}\right)-K<0
$$

for all $\left(c_{L}, c_{H}\right) \geq 0$ such that

$$
\begin{gathered}
c_{L} \geq w_{L} \\
\frac{1-\pi_{a}}{\pi_{a}} \leq\left|\frac{c_{H}-w_{H}}{c_{L}-w_{L}}\right| \leq \frac{1-\pi_{b}}{\pi_{b}},
\end{gathered}
$$

then there exists a unique equilibrium allocation with non-exclusivity characterized by:

$$
c_{H}=c_{L}=\pi_{b} w_{H}+\left(1-\pi_{b}\right) w_{L} \quad \text { and } \quad e=b .
$$

We call these equilibria low effort equilibria, represented graphically by point $c^{b}$ in Figure 2. The set of points defined by (9)-(10) is the area between the two (zero profit) lines from the endowment. Condition (8) means that from any consumption point in (9)-(10) agents strictly prefer to buy additional insurance at the price ${ }^{14}$ $\left(1-\pi_{b}\right) / \pi_{b}$ and choose effort $b$ rather than stay at that point with effort $a$ (as illustrated in Figure 2: agents prefer point $B$ rather than $A$.) In this case no allocation with high effort can be a equilibrium with non-exclusivity, because any other intermediary could make a positive profit on a contract selling insurance at a price slightly higher than $\left(1-\pi_{b}\right) / \pi_{b}$. On the other hand, insurance contracts at the price $\left(1-\pi_{b}\right) / \pi_{b}$ can never make losses. As a consequence contracts $d=\left\{d^{j}\right\}_{j \in J}$ sustaining low effort equilibrium allocations satisfy full insurance conditional on effort $b$, and zero profits for all contracts issued (i.e. $\left.\pi_{b} d_{H}^{j}+\left(1-\pi_{b}\right) d_{L}^{j}=0\right)$.

$$
<\text { Figure } 2>
$$

\footnotetext{
${ }^{14} \mathrm{By}$ 'price' of a contract we mean the ratio $\left|d_{H}^{j} / d_{L}^{j}\right|$.
} 
Proposition 3 If (8) is not satisfied at some point in (9)-(10), then any equilibrium allocation in pure strategies satisfies (9)-(10) and

$$
\pi_{a} u\left(c_{H}\right)+\left(1-\pi_{a}\right) u\left(c_{L}\right)-u\left(\pi_{b} c_{H}+\left(1-\pi_{b}\right) c_{L}\right)-K=0
$$

with $e=a$.

We call these equilibria high effort equilibria, an example of which is indicated by point $c^{a}$ in Figure 3. Condition (11) guarantees that at the high effort equilibrium allocation agents are as well off as they would be buying the optimal level of additional insurance at price $\left(1-\pi_{b}\right) / \pi_{b}$ and switching to $e=b$. A set of contracts selling insurance at price $\left(1-\pi_{b}\right) / \pi_{b}$ is offered (they never make losses), but since agents are indifferent by construction we can assume that nobody enters them in equilibrium (that is why they are called latent contracts). Latent contracts operate as a barrier to entry with respect to any other contract which offers insurance at a price lower than $\left(1-\pi_{b}\right) / \pi_{b}$. In case such a contract is offered, agents will in fact have the incentive to buy it together with all other contracts offered (including the latent contracts) and will switch to $e=b$, thereby inflicting losses not only on all the incumbents which offer contracts at price less than $\left(1-\pi_{b}\right) / \pi_{b}$, but on the entrants as well.

Since latent contracts operate as a barrier to entry, positive profits for intermediaries are possible in high effort equilibria. Positive profits are in fact always associated to high effort equilibria, under some regularity condition (cf. proof of Proposition 2A in the Appendix). An equilibrium will have a certain number $n$ of intermediaries selling each a fraction $1 / n$ of the aggregate insurance $|c-w|$, with agents being indifferent between buying from all the $n$ firms or from $n-1$ only (the indifference curve cuts twice the price line from $w$ to $c$ ). This 'local satiation' prevents firms active in equilibrium from deviating and charging a higher price for their fraction of insurance. There can be many equilibria with different numbers of active firms: in the limit as $n$ goes to infinity $c^{a}$ becomes a tangency point. As for the latent contracts, there must be at least two (or more) intermediaries each selling a divisible contract for a maximum quantity of insurance large enough: in that way agents can always buy the optimal amount in response to any entry and the intermediaries selling the latent contracts don't have profitable deviations.

$$
<\text { Figure } 3>
$$

A formal characterization of necessary conditions for high effort equilibria in terms of both allocations and contracts is contained in Proposition $2 \mathrm{~A}$ in the Appendix. ${ }^{15}$ We can also prove that, whenever conditions (8)-(10) are not satisfied, and a high

\footnotetext{
${ }^{15}$ An example for which high effort equilibria exist is presented in Hellwig (1983). Arnott-Stiglitz
} 
effort equilibrium does not exist, mixed strategy equilibria do exist (cf. the Appendix). We have not attempted to characterize mixed strategy equilibria.

We concentrate instead on the case in which agents have logarithmic utility. In this case there always exist an equilibrium in pure strategies. Moreover, explicit conditions in terms of parameter values can be obtained under which there exist low effort equilibria only.

Proposition 4 With $u()=.\ln ($.$) , there exists K_{w}$ such that low effort equilibria exist iff $v(a)-v(b)>K_{w}$. High effort equilibria exist when this condition is not satisfied; moreover high effort equilibria support allocations $\left(c_{H}, c_{L}\right)$ in (9)-(10) such that $c_{H} / c_{L}=\hat{\alpha}>1 .^{16}$

The inefficiency associated with low effort equilibria is even more striking since it also occurs for economies such that

- the incentive constrained optimal contract $d$ implements $e=a$, and

- whenever no contract at all is offered, agents choose the high effort $e=a$,

as is shown in the following proposition.

Proposition 5 Assume $u()=.\ln ($.$) . Then there exists an open set of parameters$ $\left(K, \frac{w_{H}}{w_{L}}\right)$ such that:

i) equilibria are low effort (hence they implement $e=b$ );

ii) at the constrained optimum allocation $e=a$;

iii) if no contract is offered, agents choose $e=a$.

Remark 3 It is clear from the proof that Proposition 5 does not strictly require logarithmic preferences: any sufficiently small perturbation of preferences around logs would do.

(1993) and Hellwig (1983) prove a series of propositions in the spirit of our Propositions 2 and 3. They assume that $d_{H}^{j} \leq d_{L}^{j}, \forall j \in J$ (i.e. contracts are restricted to provide positive insurance). Besides the loss of generality, that assumption complicates the analysis substantially by enlarging the set of equilibria. Hellwig (1983)'s existence example, however, does not require that restriction on the strategy set of intermediaries, and hence satisfies our definition of equilibrium with nonexclusivity.

${ }^{16}$ In the proof of the proposition it is also shown that $\hat{\alpha}$ is the minimum over the set of solutions to the equation $\exp \{-K\} \alpha^{\pi_{a}}=\left(1-\pi_{b}\right)+\pi_{b} \alpha$. With $\log$ utility, the points satisfying (11) lie on two lines from the origin, as drawn in Figure 3. 
Finally we are ready to study third best efficiency. Suppose that the planner chooses transfers to agents knowing that, at the new endowments determined by the transfers, agents will trade up to an equilibrium with non-exclusivity. Is the planner able to improve agents' expected utility? This is the question our analysis of third best efficiency asks. The answer is in general yes for economies with high effort equilibria. No Pareto improving transfers are on the contrary possible for economies with low effort equilibria.

It is easy to give an intuition for this result, based on the characterization of high effort equilibria developed to this point. Proposition 3 shows that high effort equilibria are supported by 'latent' contracts. These contracts form a barrier to entry. From the efficiency point of view, 'latent' contracts have two effects. On the positive side, they endogenously restrict entry of contracts which provide a negative externality on the incentives of the incumbent contracts which support the 'high' effort. On the negative side 'latent' contracts, acting as a barrier to entry in general, limit the scope of competition across intermediaries. This negative effect manifests itself obviously as positive profits of intermediaries in equilibrium. While 'latent' contracts play the role of restricting entry also at the third best allocation, the planner's transfers can always be chosen so that intermediaries are not able to extract any rent from agents trading after having received the transfers.

Proposition 6 Low effort equilibria are third best efficient. High effort equilibria are third best inefficient for a generic set of parameters.

We give here a sketch of the proof of Proposition 6, with the help of Figure 3, because it is quite instructive. Roughly, the proof shows that the third best efficient allocation naturally implies zero profit for the intermediaries, while at equilibrium profits are positive because 'latent' contracts endogenously generate a barrier to entry. The details of the proof are in the Appendix.

Sketch of the proof. Any low effort equilibrium is third best efficient. In fact, if conditions (8)-(10) are satisfied, given any transfer $\left|\frac{\tau_{H}}{\tau_{L}}\right|<\frac{1-\pi_{b}}{\pi_{b}}$, the equilibrium with non-exclusivity after the transfer will have agents choose $e=b$. As a consequence the transfers do not satisfy the resource constraint (7). Any transfer $\left|\frac{\tau_{H}}{\tau_{L}}\right|=\frac{1-\pi_{b}}{\pi_{b}}$ has no effect on the equilibrium after the transfer.

Suppose now that (8)-(10) are not satisfied. Let us first characterize the third best efficient allocation $c^{t b}=\left(c_{H}^{t b}, c_{L}^{t b}\right)$ with high effort. The resource constraint (7) for transfers and non-negative profits for intermediaries require

$$
\begin{gathered}
c_{L} \geq w_{L} \\
\frac{1-\pi_{a}}{\pi_{a}} \leq\left|\frac{c_{H}-w_{H}}{c_{L}-w_{L}}\right|
\end{gathered}
$$


Graphically (see Figure 3), $c^{t b}$ is restricted to be on or below the high effort zero profit line (the other inequality previously in (10) is not binding here). The crucial step is to note that to guarantee feasibility of the planner's transfers (equation (7)), $c^{t b}$ must be such that, at the equilibrium allocation which will be reached after the transfers, the agents choose the high effort; this implies that $c^{t b}$ must satisfy

$$
\pi_{a} u\left(c_{H}\right)+\left(1-\pi_{a}\right) u\left(c_{L}\right)-u\left(\pi_{b} c_{H}+\left(1-\pi_{b}\right) c_{L}\right)-K \geq 0
$$

The third best allocation $c^{t b}$ will then be a point maximizing agents' expected utility s.t. (9), (10), and (12). In fact at the third best allocation (12) will be satisfied with equality (which is equation (11) above). As a consequence, $c^{t b}$ will be either a point of intersection of (11) with the zero profit line (as in the log example shown in Figure 3, where the lower branch of (11) is a line with positive slope) or a point below the zero profit line with the indifference curve tangent to (11) (in cases where (11) might bend backward). We consider here only the first case, as represented in Figure 3, and refer to the Appendix for the complete case, in which possibly positive profits arise at the third best (in this case the same intuition holds in the modified sense that the high effort equilibrium displays higher profits for intermediaries than the third best).

We can now show that a point of intersection of (11) with the zero profit line, as $c^{t b}$, cannot be an equilibrium with non-exclusivity. To be an equilibrium for some number of active firms $n$, the indifference curve should cut the line twice, at $c^{t b}=w+d$ and at $w+\frac{n-1}{n} d$, or in the limit with $n \rightarrow \infty$ be tangent (Prop. 3). But with effort $e=a$, indifference curves have a slope $\left(1-\pi_{a}\right) / \pi_{a}$ at full insurance and a steeper slope in the region of underinsurance. In this region, then, they can only cut the zero profit line once from above. Therefore $c^{t b}$ cannot be supported as a high effort equilibrium.

Remark 4 The assumption that the planner can set transfer before markets open, in the definition of third best optimum, is not essential. A similar inefficiency results could be derived if we simply had the planner choose contracts simultaneously with intermediaries provided the planner of course maximizes agents' preferences.

\section{Concluding Remarks}

We have shown in a hidden action model that non-exclusivity of contractual arrangements has possibly dramatic effects on the contracts traded in equilibrium and on the equilibrium allocations and action. In particular for an open set of economies the optimal action is not implemented in equilibrium, and for the economies in which it is implemented, some intermediaries make positive profits and allocations are third best inefficient. 
Similar inefficiencies due to non-exclusivity of contracts arise also in different asymmetric information economies (cf. Bisin-Guaitoli (1995)). For instance in the hidden information insurance economies studied by Townsend (1982), no insurance contract is traded at the equilibrium with non-exclusivity, even though insurance contracts are sustained at the incentive constrained optimum.

Also, in the information extraction economy studied by Ma (1988), the information which can be extracted from agents at the equilibrium with non-exclusivity is very limited, even though information is fully extracted at the incentive constrained optimum (thereby sustaining first best allocations). 


\section{Appendix 1: Existence}

We first sketch here a proof of existence in mixed strategies for completeness. The proof follows the lines of Bisin (1998).

The agents' optimal choice in problem 1-2) is described by a mapping from $\left\{d^{h}\right\}_{h \in H}$ into $(e, \lambda, c)$. Let this mapping be denoted $\psi$. Then clearly, under the assumptions on preferences, $\psi$ is upper-hemi-continuous.

We can now restrict the set of feasible contracts, without loss of generality as follows: $d_{L}^{j} \in\left[-w_{L},+w_{L}\right], d_{H}^{j} \in\left[-w_{H},+w_{H}\right], \forall j \in J$. The strategy space of the game played by intermediaries is then compact, and their payoff function is a continuous function of $(e, \lambda, c)$. Intermediaries rationally anticipate the map $\psi$ of $\left\{d^{h}\right\}_{h \in H}$ into $(e, \lambda, c)$. In fact, because there is a continuum of agents $i \in I$, intermediaries rationally anticipate the convex hull of $\psi$ (cf. Bisin (1998)). Intermediaries' profits are then effectively an upper-hemi-continuous convex valued correspondence, since they are a continuous function of $\psi$. The main theorem in Simon-Zame (1990) allows finally to show that, for some selection of the intermediaries' profit correspondence, a Nash equilibrium in mixed strategies of the game exists. $\diamond$

\section{Appendix 2: Proofs}

Let $c(u)$ denote the inverse of preferences $u(c)$.

Lemma 1 The incentive constrained optimum allocation with effort $e=$ a for any agent $i \in I$ is a solution of the following (dual) problem:

$$
\begin{gathered}
\left\{u_{H}, u_{L}\right\}=\operatorname{argmin} \pi_{a} c\left(u_{H}\right)+\left(1-\pi_{a}\right) c\left(u_{L}\right) \\
\text { s.t. } \quad \pi_{a} u_{H}+\left(1-\pi_{a}\right) u_{L}-v(a) \geq \bar{U} \\
\pi_{a} u_{H}+\left(1-\pi_{a}\right) u_{L}-v(a) \geq \pi_{b} u_{H}+\left(1-\pi_{b}\right) u_{L}-v(b) .
\end{gathered}
$$

If a solution exists for given $\bar{U} \geq \pi_{a} u\left(w_{H}\right)+\left(1-\pi_{a}\right) u\left(w_{L}\right)-v(a)$, then both the participation constraint and the incentive constraints are binding.

Proof of Lemma 1. The first order conditions for $u_{H}$ and $u_{L}$ are

$$
\begin{gathered}
\pi_{a} c^{\prime}\left(u_{H}\right)-\lambda \pi_{a}-\mu\left(\pi_{a}-\pi_{b}\right)=0 \\
\left(1-\pi_{a}\right) c^{\prime}\left(u_{L}\right)-\lambda\left(1-\pi_{a}\right)+\mu\left(\pi_{a}-\pi_{b}\right)=0
\end{gathered}
$$

where $\lambda$ and $\mu$ are the (non-negative) multipliers for the participation and the incentive constraints. Substituting $\lambda$ we get

$$
c^{\prime}\left(u_{H}\right)-c^{\prime}\left(u_{L}\right)=\mu \frac{\pi_{a}-\pi_{b}}{\pi_{a}\left(1-\pi_{a}\right)} .
$$


Suppose by contradiction that the incentive constraint is not binding: then $\mu=0$ implies $c^{\prime}\left(u_{L}\right)=c^{\prime}\left(u_{H}\right)$, hence $u_{H}=u_{L}$ (full insurance), which is not incentive compatible (since $v(a)>v(b)$ ). Now suppose the participation constraint is not binding: with utility functions unbounded below, if we decrease $u_{H}$ and $u_{L}$ by the same amount until the constraint is binding, the incentive constraint is unchanged and the value of the objective function which we want to minimize is reduced. $\diamond$

The following Proposition 2A collects in a more precise form the statements of Propositions 2 and 3 in the text. In this Appendix we prove directly Proposition $2 \mathrm{~A}$ (cf. also Figures 2 and 3).

Let $P_{j}$ be the profits made by the intermediary who issues contract $j$ (out of contract $j$ only).

Proposition 2A For the hidden action model there exist equilibria with nonexclusivity characterized as follows:

1. if

$$
\pi_{a} u\left(c_{H}\right)+\left(1-\pi_{a}\right) u\left(c_{L}\right)-u\left(\pi_{b} c_{H}+\left(1-\pi_{b}\right) c_{L}\right)-K<0,
$$

for all $\left(c_{L}, c_{H}\right)$ such that

$$
\begin{gathered}
c_{L} \geq w_{L}^{i} \\
\frac{1-\pi_{a}}{\pi_{a}} \leq\left|\frac{c_{H}-w_{H}^{i}}{c_{L}-w_{L}^{i}}\right| \leq \frac{1-\pi_{b}}{\pi_{b}}
\end{gathered}
$$

then

1a) $c_{H}=c_{L}=\pi_{b} w_{H}+\left(1-\pi_{b}\right) w_{L}$ and $e=b$ are the unique equilibrium allocations and effort choice; the equilibrium contracts $d=\left\{d^{j}\right\}_{j \in J}$ sustaining this allocation and effort satisfy:

1b) $\pi_{b} d_{H}^{j}+\left(1-\pi_{b}\right) d_{L}^{j}=0, \forall j \in J$; moreover

1c) $P_{j}=0, \forall j \in J$;

2. if (8) is not satisfied at some point in (9)-(10), then

2a) any pure strategy equilibrium allocation $\left(c_{H}, c_{L}\right)$ satisfies (9)-(10) and

$$
\pi_{a} u\left(c_{H}\right)+\left(1-\pi_{a}\right) u\left(c_{L}\right)-u\left(\pi_{b} c_{H}+\left(1-\pi_{b}\right) c_{L}\right)-K=0
$$

with $e=a$; moreover the equilibrium contracts $d=\left\{d^{j}\right\}_{j \in J}$ sustaining this allocation and effort satisfy: 
2b) $\exists J_{1} \subset J$ and $n$ such that:

$\pi_{a} d_{1 H}^{j}+\left(1-\pi_{a}\right) d_{1 L}^{j} \leq 0$ (and, for a generic set of economies, also $d_{1}^{j}=$ $\left.\frac{1}{n}|c-w|\right), \forall j \in J_{1}$

$\forall j \in J_{2}=J-J_{1}$

$\pi_{b} d_{2 H}^{j}+\left(1-\pi_{b}\right) d_{2 L}^{j}=0$ and $\Lambda_{j}=[0,1]$

2c) $P_{j}=0$ and $\lambda_{j}=0, \forall j \in J_{2}$; while

$P_{j}\left\{\begin{array}{ll}>0 & \text { if } \frac{1-\pi_{a}}{\pi_{a}}<\left|\frac{c_{H}-w_{H}^{i}}{c_{L}-w_{L}^{i}}\right| \\ =0 & \text { if } \frac{1-\pi_{a}}{\pi_{a}}=\left|\frac{c_{H}-w_{H}^{i}}{c_{L}-w_{L}^{i}}\right|\end{array} \mid, \forall j \in J_{1}\right.$.

2d) if $\frac{1-\pi_{a}}{\pi_{a}}=\left|\frac{c_{H}-w_{H}^{i}}{c_{L}-w_{L}^{i}}\right|$ there may also be equilibria with properties 1a-c); moreover an equilibrium in mixed strategies exists whenever equilibria 2a-c) fail to exist.

Proof of Proposition 2A. Equilibria are characterized in terms of aggregate allocation (there may be many equilibria of the game that differ only for the allocation of sales and profits among individual firms, but imply the same effort and consumption allocation for agents, as well as the same aggregate sales and profits). Define $c=\left(c_{L}, c_{H}\right)$ and $U(c, e)=\pi_{e} u\left(c_{H}\right)+\left(1-\pi_{e}\right) u\left(c_{L}\right)-v(e)$.

Step 1. Trivially any equilibrium allocation must satisfy (9)-(10) (outside that region either profits are negative or there is always room for another profitable contract). Consider the allocations $\left(c_{L}, c_{H}\right)$ satisfying

$$
\pi_{a} u\left(c_{H}\right)+\left(1-\pi_{a}\right) u\left(c_{L}\right)-v(a)<\pi_{b} u\left(c_{H}-\frac{1-\pi_{b}}{\pi_{b}} \hat{d}\right)+\left(1-\pi_{b}\right) u\left(c_{L}+\hat{d}\right)-v(b),
$$

where

$$
\hat{d}=\operatorname{argmax}\left\{\pi_{b} u\left(c_{H}-\frac{1-\pi_{b}}{\pi_{b}} d\right)+\left(1-\pi_{b}\right) u\left(c_{L}+d\right)\right\} .
$$

By concavity $\hat{d}$ implies full insurance (conditioned on effort $b$ ); substituting we obtain condition (8). No such allocation can be sustained as an equilibrium because, for some small positive $\epsilon, d^{\prime}$ s.t. $\pi_{b} d_{H}^{\prime}+\left(1-\pi_{b}\right) d_{L}^{\prime}=-\epsilon$ is a strict best reply to any $d$ sustaining $\left(c_{L}, c_{H}\right)$. Only allocations 1a) (full insurance with low effort) can be sustained in equilibrium, since $d^{\prime}$ s.t. i) $\pi_{b} d_{H}^{\prime}+\left(1-\pi_{b}\right) d_{L}^{\prime}=0$ and ii) $d_{L}^{\prime} \geq 0$ ('positive insurance'), is weak best reply to $d=\left\{d^{j}\right\}_{j \in J}$ s.t. $\left|d_{H}^{j} / d_{L}^{j}\right|=\left(1-\pi_{b}\right) / \pi_{b}$, for any $J$.

Step 2. If (8) is violated at some points in (9)-(10), there exists a non-empty set of allocations $\left(c_{L}, c_{H}\right)$ for which (11) is satisfied (by continuity, since (8) is always satisfied when $c_{L}=c_{H}$ ). No allocation with high effort for which the left-hand side of (11) is negative (as in (8)) can be a equilibrium (from Step 1). Suppose the lefthand side of (11) is strictly positive at the allocation $\left(c_{L}, c_{H}\right)$ sustained by contracts 
$d=\left\{d^{j}\right\}_{j \in J}$ s.t.

$$
c_{s}=w_{s}+\sum_{j \in J} d_{s}^{j}, \quad s=H, L
$$

In the region of underinsurance the marginal rate of substitution is greater than the zero profit rate, i.e.

$$
\frac{1-\pi_{a}}{\pi_{a}} \frac{u^{\prime}\left(c_{L}\right)}{u^{\prime}\left(c_{H}\right)}>\frac{1-\pi_{a}}{\pi_{a}} \quad \text { if } \quad c_{L}<c_{H} .
$$

Then there is always another profitable contract $d^{\prime}$ s.t. $U\left(c+d^{\prime}, a\right)>U(c, a)$ and $U\left(c+d^{\prime}, a\right)>U\left(c+d^{\prime}, b\right)$ (compare (11) with the incentive constraint in Lemma 1). However the allocation $\left(c_{L}, c_{H}\right)$ could be sustained by a set of contracts $d$ including not only those needed to reach the consumption point, i.e. $\left\{d_{1}^{j}\right\}_{j \in J_{1}}$ s.t.

$$
c_{s}=w_{s}+\sum_{j \in J_{1}} d_{1}^{j} s, \quad s=H, L
$$

but also 'stand-by' or 'latent' contracts that deter entry, i.e. $\left\{d_{2}^{j}\right\}_{j \in J_{2}=J-J_{1}}$ s.t.

$$
\max _{\lambda_{j} \in[0,1]} U\left(c+\sum_{j \in J_{2}} \lambda_{j} d_{2}^{j}, b\right)=U(c, a)
$$

and if $U\left(c+d^{\prime}, a\right)>U(c, a)$, then

$$
\max _{\lambda_{j} \in[0,1]} U\left(c+d^{\prime}+\sum_{j \in J_{2}} \lambda_{j} d_{2}^{j}, b\right)>U\left(c+d^{\prime}, a\right)
$$

Here the following Lemma applies.

Lemma 2 The set of contracts sustaining an equilibrium with $e=$ a must include 'latent' contracts $\left\{d_{2}^{j}\right\}_{j \in J_{2}}$ s.t. $\lambda_{j}=0, \forall j \in J_{2}$; moreover any latent contract must satisfy $\pi_{b} d_{2 H}^{j}+\left(1-\pi_{b}\right) d_{2 L}^{j}=0, \forall j \in J_{2}$.

Proof of Lemma 2. If no latent contracts are issued, for any proposed allocation $c$ there always exists another profitable contract: see Prop. 1 for points on the incentive constrained frontier and Step 2 above for other points. Suppose latent contracts provide additional insurance at a price $\left|d_{2 H}^{j} / d_{2 L}^{j}\right|<\left(1-\pi_{b}\right) / \pi_{b}$, for any $j \in J_{2}$. Agents will be indifferent between the candidate equilibrium allocation $c$ with high effort $a$ and the best point they can reach with the latent contracts, $\hat{c}=\operatorname{argmax} U\left(c^{\prime}, b\right)$ s.t. $c^{\prime}=c+\sum \lambda_{j} d_{2}^{j}$, which will be in the region of overinsurance (where the marginal rate of substitution with low effort is less than $\left.\left(1-\pi_{b}\right) / \pi_{b}\right)$. But then there exists a contract $d^{\prime}$ selling negative insurance (i.e. $d_{L}^{\prime}<0, d_{H}^{\prime}>0$ ) with $\left|d_{2 H} / d_{2 L}\right|<\left|d_{H}^{\prime} / d_{L}^{\prime}\right|<\left(1-\pi_{b}\right) / \pi_{b}$, such that $U\left(\hat{c}+d^{\prime}, b\right)>U(\hat{c}, b)=U(c, a)$ 
(agents strictly prefer the low effort allocation with latent contracts and the negative insurance). Also, by the definition of equilibrium, this is better than adding the negative insurance to $c$ with high effort, i.e. $U\left(\hat{c}+d^{\prime}, b\right)>U\left(c+d^{\prime}, a\right)$. If such a contract is introduced, agents will then buy all the contracts and choose low effort. Any contract selling positive insurance with a slope less than $\left(1-\pi_{b}\right) / \pi_{b}$ will make losses, but $d^{\prime}$ being the negative of such a contract will make positive profits. Suppose now the aggregate quantity of insurance offered by such latent contracts is rationed so that agents cannot reach the region of overinsurance, but only points of underinsurance or a point of full insurance: then in the first case additional positive insurance at a price slightly higher than $\left(1-\pi_{b}\right) / \pi_{b}$ is a profitable deviation; while in the second case any one firm selling part of the latent can unilaterally deviate to a profitable contract, since the remaining quantity of the latent contracts will be insufficient to trigger the agents' reaction (even in the limit with an infinite number of intermediaries selling each an infinitesimal amount of the latent contracts, given that the full insurance point is not a point of tangency, i.e. of local satiation). A profitable deviation exists, then, for any candidate equilibrium supported by latent contracts at a price less than $\left(1-\pi_{b}\right) / \pi_{b}$. The only equilibrium contracts that survive are those supported by latent contracts at a price $\left|d_{2 H}^{j} / d_{2 L}^{j}\right|=\left(1-\pi_{b}\right) / \pi_{b}$, for any $j \in J_{2}$. To trigger agents' reaction for any possible entry, these contracts must be available in any quantity (i.e. they have to be divisible) up to a large enough maximum. To be a best reply for firms, the number of intermediaries selling the latent contracts must be, say, $m \geq 2$, with the aggregate quantity offered by any $m-1$ firms large enough to satiate agents for any possible deviations (e.g. $d_{2 H}^{j}=-w_{H}$ for any $j \in J_{2}$ ). $\diamond$ Any equilibrium allocation sustained by latent contracts (according to Lemma 2) by definition must satisfy (11): more precisely, it must belong to the subset of (11) made of points $c$ s.t. $c_{L}>c_{L}^{\prime}$ for any $c^{\prime}$ in (11) with $\pi_{b} c_{H}^{\prime}+\left(1-\pi_{b}\right) c_{L}^{\prime}=\pi_{b} c_{H}+\left(1-\pi_{b}\right) c_{L}$. Latent contracts deter entry, but also firms that are active in equilibrium must be prevented from deviating and charging a higher price for their part of the aggregate insurance. If $U(c, a)>U\left(c-d^{j}, a\right)$ for some $j \in J_{1}$, there is some contract $d^{j^{\prime}}$ (with a higher price) which is more profitable than $d^{j}$. The equilibrium requires $U(c, a)=U\left(c-d^{j}, a\right)$ for all $j \in J_{1}$ : with $n$ firms selling, this 'local satiation' implies $d_{1}^{j}=\frac{1}{n}|c-w|$; isoprofit lines have a slope $\left(1-\pi_{a}\right) / \pi_{a}$, less steep than the indifference curve, so no deviation is profitable. Such equilibria exist e.g. when the utility of consumption takes the form $u(c)=c^{\gamma} / \gamma, \gamma<0$ or $u(c)=\ln c$ (as proved by Hellwig (1983)). ${ }^{17}$ If no equilibrium in pure strategies exists, however, we can prove that an equilibrium in mixed strategies always exists (cf. Appendix 1). To complete the proof of $2 \mathrm{~d}$ ), suppose the equilibrium allocation $c$ with the property

\footnotetext{
${ }^{17}$ It can also be shown that equilibria which do not satisfy $d_{1}^{j}=\frac{1}{n}|c-w|, \forall j \in J_{1}$, might exist only for a set of economies for which (12) is not transversal to 0 . This set of economies is non-generic, as it can immediately be proved using perturbations of the parameter $K$.
} 
stated in 2d) (with all contracts making zero profits) is the only point satisfying (9)-(10) and (11). Weak best replies to $\left\{d_{2}^{j}\right\}_{j \in J_{2}}$ as in Lemma 2 are both other contracts of the same kind or contracts $\left\{d_{1}^{j}\right\}_{j \in J_{1}}$ s.t. $c=w+d_{1}$. Hence both type of equilibria may coexist. $\diamond$

Proof of Proposition 4. With log utility, condition (8) becomes

$$
\exp \{-K\}\left(\frac{c_{H}}{c_{L}}\right)^{\pi_{a}}<\left(1-\pi_{b}\right)+\pi_{b}\left(\frac{c_{H}}{c_{L}}\right)
$$

Denote $\alpha \equiv c_{H} / c_{L}$. If $K$ is sufficiently small, the left hand side will have two intersections $\hat{\alpha_{1}}$ and $\hat{\alpha_{2}}$ with the right hand side. Condition (8) is violated by points $c$ s.t. $c_{H} / c_{L} \in\left[\hat{\alpha_{1}}, \hat{\alpha_{2}}\right]$. The greater $K$, i.e. the marginal disutility of effort, the closer $\hat{\alpha_{1}}$ and $\hat{\alpha_{2}}$; for $K$ equal to

$$
K^{\prime} \equiv \pi_{a} \ln \left(\frac{\pi_{a}}{\pi_{b}}\right)+\left(1-\pi_{a}\right) \ln \left(\frac{1-\pi_{a}}{1-\pi_{b}}\right)
$$

a singularity is reached at

$$
\hat{\alpha}=\frac{\left(1-\pi_{b}\right) \pi_{a}}{\left(1-\pi_{a}\right) \pi_{b}}
$$

(points at which the marginal rate of substitution conditioned on effort $a$ is equal to $\left.\left(1-\pi_{b}\right) / \pi_{b}\right)$. For $K>K^{\prime}(8)$ is satisfied by any $c$. A threshold $K_{w}=K^{\prime}$ therefore is always a sufficient condition, but it is really necessary only if $\left(w_{H} / w_{L}\right) \geq \frac{\left(1-\pi_{b}\right) \pi_{a}}{\left(1-\pi_{a}\right) \pi_{b}}$ (i.e. if the endowment point lies to the left of the singular $\hat{\alpha}$ ). Otherwise it is sufficient (and necessary) that the smaller $\hat{\alpha_{1}}$ be greater than $w_{H} / w_{L}$ (so no point satisfying (9) can violate (8)). In this case take $K_{w}=K^{\prime \prime}<K^{\prime}$, with $K^{\prime \prime}$ s.t. $\hat{\alpha_{1}}=w_{H} / w_{L}$. The rest follows from Proof of Prop. $2 \mathrm{~A} . \diamond$

Proof of Proposition 5. Define $\theta=w_{H} / w_{L}$. With logarithmic preferences, for any given $\left(\pi_{a}, \pi_{b}\right)$ there exists an open set $K>K^{\prime}, \theta>\theta^{\prime}$ such that $e=b$ at any equilibrium (from the proof of Proposition 4 with $\theta^{\prime}=\frac{\left(1-\pi_{b}\right) \pi_{a}}{\left(1-\pi_{a}\right) \pi_{b}}$ ). At the incentive constrained optimum with $e=a$ the incentive constraint is binding (Lemma 1): $u_{H}-u_{L}=\frac{K}{\pi_{a}-\pi_{b}}$, i.e. $c_{H}=\exp \left\{\frac{K}{\pi_{a}-\pi_{b}}\right\} c_{L}$; substituting into the zero-profit condition:

$$
c_{L}=\frac{w_{L}+\pi_{a}\left(w_{H}-w_{L}\right)}{1-\pi_{a}+\pi_{a} \exp \left\{K /\left(\pi_{a}-\pi_{b}\right)\right\}} .
$$

Furthermore, with zero profits the agents' expected utility must be higher than the maximum utility attainable with $e=b$, i.e.

$$
\pi_{a} u_{H}+\left(1-\pi_{a}\right) u_{L}-v(a) \geq u\left(\pi_{b} w_{H}+\left(1-\pi_{b}\right) w_{L}\right)-v(b) .
$$


Using the incentive constraint and the expression for $c_{L}$, the last condition can be written as

$$
\frac{1+\pi_{a}(\theta-1)}{1+\pi_{b}(\theta-1)} \geq \frac{1-\pi_{a}+\pi_{a} \exp \left\{K /\left(\pi_{a}-\pi_{b}\right)\right\}}{\exp \left\{\pi_{b} K /\left(\pi_{a}-\pi_{b}\right)\right\}} .
$$

Since the left hand side is increasing in $\theta$, for any given $\left(\pi_{a}, \pi_{b}\right)$ and $K>K^{\prime}$ there exists an open set $\theta>\theta^{\prime \prime}$ such that $e=a$ at any incentive constrained optimum allocation. Hence there exists an open set $K>K^{\prime}, \theta>\max \left(\theta^{\prime}, \theta^{\prime \prime}\right)$ such that conditions i) and ii) are satisfied. Finally, for $\theta>\exp \left\{K /\left(\pi_{a}-\pi_{b}\right)\right\}$, even if no contract is offered, $e=a$ (i.e. iii) is satisfied), since the endowment point is in the interior of the incentive constrained allocations. $\diamond$

Proof of Proposition 6. Given the sketch in the text, it remains to prove that $c^{t b}$ cannot be supported as an equilibrium with non-exclusivity even if $c^{t b}$ is below the zero profit line, with the indifference curve tangent to equation (11). This is the only case remaining to consider, since i) (11) defines a differentiable manifold in any compact contained in $\Re_{++}^{2}$, and ii) the region $\left(c_{H}, c_{L}\right)$ defined by $(12)$ is generically transversal to 0 (trivially, by perturbing $K$ ). Hence the planning problem is characterized by the tangency of an indifference curve with the manifold defined by (11). At any equilibrium with high effort, the slope of the indifference curve is less than $\left(1-\pi_{b}\right) / \pi_{b}$ in absolute value. As a consequence, on the latent contract line with slope $\left(1-\pi_{b}\right) / \pi_{b}$ through the equilibrium, there lie allocations which provide less insurance to the agent and which satisfy (12) strictly; i.e. allocations at which agents strictly prefer not to buy the latent contracts. Hence (11) must have a slope steeper than $\left(1-\pi_{b}\right) / \pi_{b}$ at the equilibrium and cannot be tangent to the indifference curve. This directly implies that $c^{t b}$ cannot be supported as a high effort equilibrium. $\diamond$ 


\section{References}

Aleem, I. (1990): 'Imperfect Information, Screening and the Costs of Informal Lending: A Study of Rural Credit Markets in Pakistan', World Bank Economic Review, 4, 329-49.

Al-Najjar, N. (1995): 'Decomposition and Characterization of Risk with a Continuum of Random Variables', Econometrica, 63, 1195-224.

Arnott R. and J. Stiglitz (1992): 'The Welfare Economics of Moral Hazard', NBER Working Paper n. 3316.

Arnott R. and J. Stiglitz (1993): 'Equilibrium in Competitive Insurance Markets with Moral Hazard', mimeo, Boston College.

Atkinson A. and R. Lucas (1992): 'On Efficient Distribution with Private Information', Review of Economic Studies, 59, 427-53.

Bencivenga V. and B. Smith (1991): 'Financial Intermediation and Endogenous Growth', Review of Economic Studies,58, 195-209.

Bennardo, A. and P. A. Chiappori (1998): 'Competition, Positive Profits and Market Clearing under Asymmetric Information', mimeo, University of Chicago.

Bernheim, B. and M. Whinston (1986): 'Common Agency', Econometrica, 54, 92342.

Bertini, B. (1967): Manuale delle Cessioni Stipendio, Grafiche Artigianelli.

Bisin A. (1998): 'General Equilibrium with Endogenously Incomplete Financial Markets, Journal of Economic Theory, forthcoming.

Bisin A. and P. Gottardi (1997): 'General Competitive Analysis with Asymmetric Information', C.V. Starr Center RR\# 97-38.

Bisin A. and D. Guaitoli (1995): 'Inefficiency of Competitive Equilibrium with Asymmetric Information and Financial Intermediaries', mimeo, Universitat Pompeu Fabra. Bizer, D. and P. de Marzo (1992): 'Sequential Banking', Journal of Political Economy, 100, 41-61.

Diamond, P. and J. Mirlees (1996): 'Social Insurance with Variable Retirement and Private Savings', mimeo, MIT.

Gibbons, R. (1997): 'Incentives and Careers in Organizations', in D. Kreps and K. Wallis (eds.), Advances in Economics and Econometrics: Theory and Applications; Seventh World Congress, Vol. II, Cambridge University Press.

Greenwood J. and B. Jovanovic (1990): 'Financial Development, Growth and the Distribution of Income', Journal of Political Economy, 98, 1076-1107.

Guesnerie, R. (1995): A Contibution to the Pure Theory of Taxation, Cambridge University Press, Cambridge.

Guiso, L., T. Jappelli and D. Terlizzese (1991): 'Why is Italy's Savings Rate so High?', CEPR Discussion Paper 572.

Hart, O. and B. Holmstrom (1987): 'The Theory of Contracts', in T. Bewley (ed.), 
Advances in Economic Theory: Fifth World Congress, Cambridge University Press. Hellwig M. (1983): 'On Moral Hazard and Non-price Equilibria in Competitive Insurance Markets', mimeo, University of Bonn.

Helpman, E. and J. J. Laffont (1975): 'On Moral Hazard in Equilibrium Theory', Journal of Economic Theory, 10, 8-23.

Hoff, K. and J. Stiglitz (1997): 'Moneylenders and Bankers: Price-Increasing Subsidies in a Monopolistically Competitive Market, Journal of Development Economics, 52, 429-62.

Jaynes, G. (1978): 'Equilibria in Monopolistically Competitive Insurance Markets', Journal of Economic Theory, 19, 394-422.

Kahn, C. and D. Mookherjee (1997): 'Competition and Incentives with Non-Exclusive Contracts', mimeo, Boston University.

Kotlikoff, L. and A. Spivak (1981): 'The Family as an Incomplete Annuity Market', Journal of Political Economy, 89(2), 372-91.

Ma, C. T. (1988): 'Unique Implementation of Incentive Contracts with Many Agents', Review of Economic Studies, 55, 555-71.

Mas Colell, A. (1982): 'The Cournotian Foundations of Walrasian Equilibrium Theory: An Exposition of Recent Theory', in W. Hildenbrand (ed.), Advances in Economic Theory, Cambridge University Press.

McKinnon, R. I. (1973): Money and Capital in Economic Development, Brookings Institution.

Morduch, J. (1997): 'The Microfinance Revolution', mimeo, Harvard University.

Pauly, M. (1968): 'The Economics of Moral Hazard', American Economic Review, 58, 31-58.

Petersen, M. and R. Rajan (1994): 'The Benefits of Lending Relationsips: Evidence from Small Business Data', Journal of Finance, 49, 3-37.

Prescott E. and R. Townsend (1984): 'Pareto Optima and Competitive Equilibria with Adverse Selection and Moral Hazard', Econometrica, 52, 21-45.

Rothschild M. and J. Stiglitz (1976): 'Equilibrium in Competitive Insurance Markets', Quarterly Journal of Economics, 80, 629-49.

Shaw, E. (1973): Financial Deepening in Economic Development, Oxford University Press.

Siamwalla, A., et al. (1990): 'The Thai Rural Credit System: Public Subsidies, Private Information, and Segmented Markets', World Bank Economic Review, 4, 27195.

Simon, L. and W. Zame (1990): 'Discountinuous Games and Endogenous Sharing Rules', Econometrica, 58, 861-72.

Smith, C. and J. Warner (1979): 'On Financial Contracting: An Analysis of Bond Covenants', Jornal of Financial Economics, 7, 117-61.

Townsend R. (1982): 'Optimal Multiperiod Contracts and the Gain from Enduring 
Relationships', Journal of Political Economy, 90, 1166-86.

Townsend, R. (1987): 'Arrow-Debreu Programs as Microfoundations of Macroeconomics', in Bewley (ed.), Advances in Economic Theory: Fifth World Congress, Cambridge University Press.

Townsend R. (1994): 'Risk and Insurance in Village India', Econometrica, 62, 53991. 
FIGURE 1

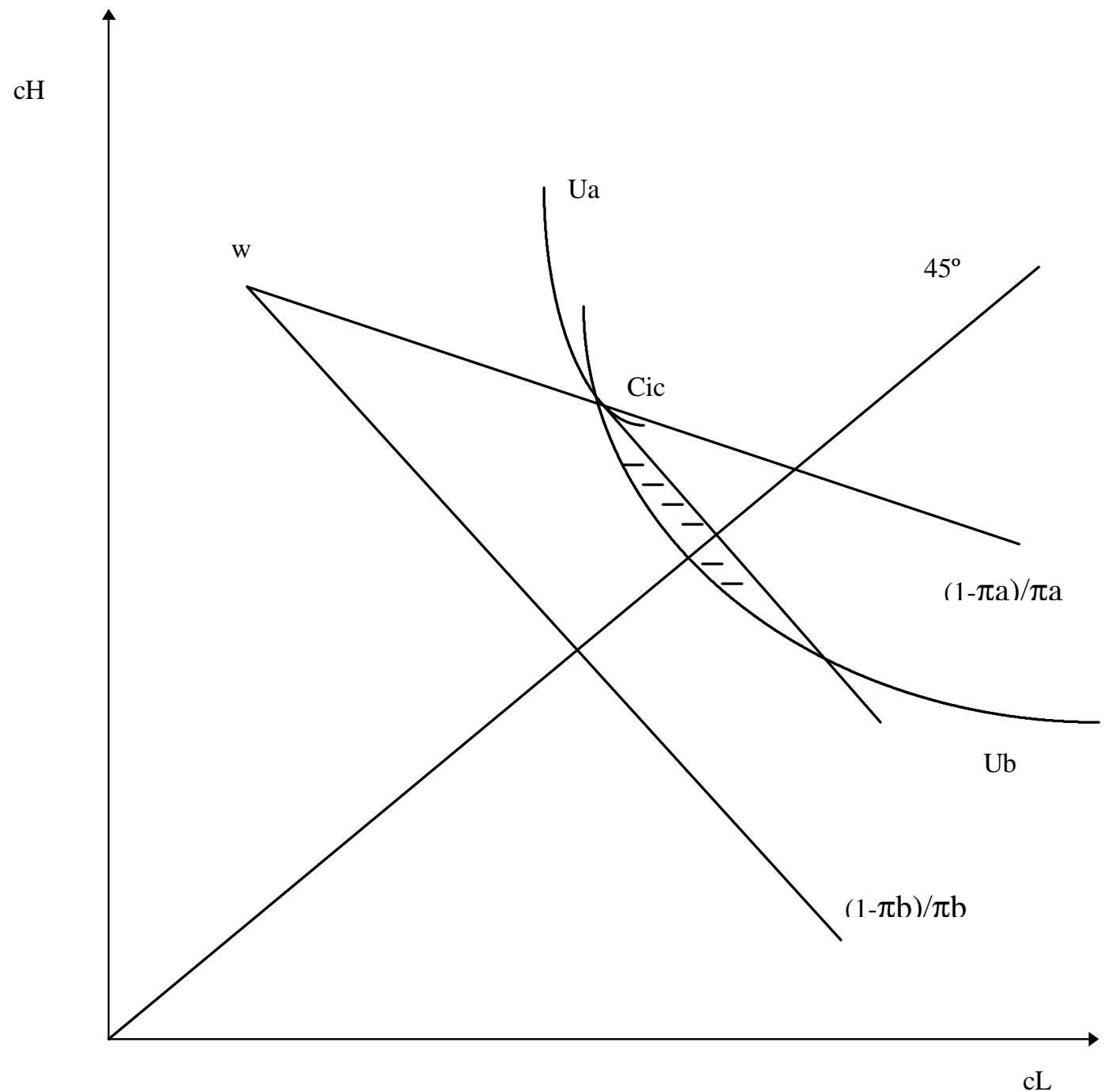


FIGURE 2

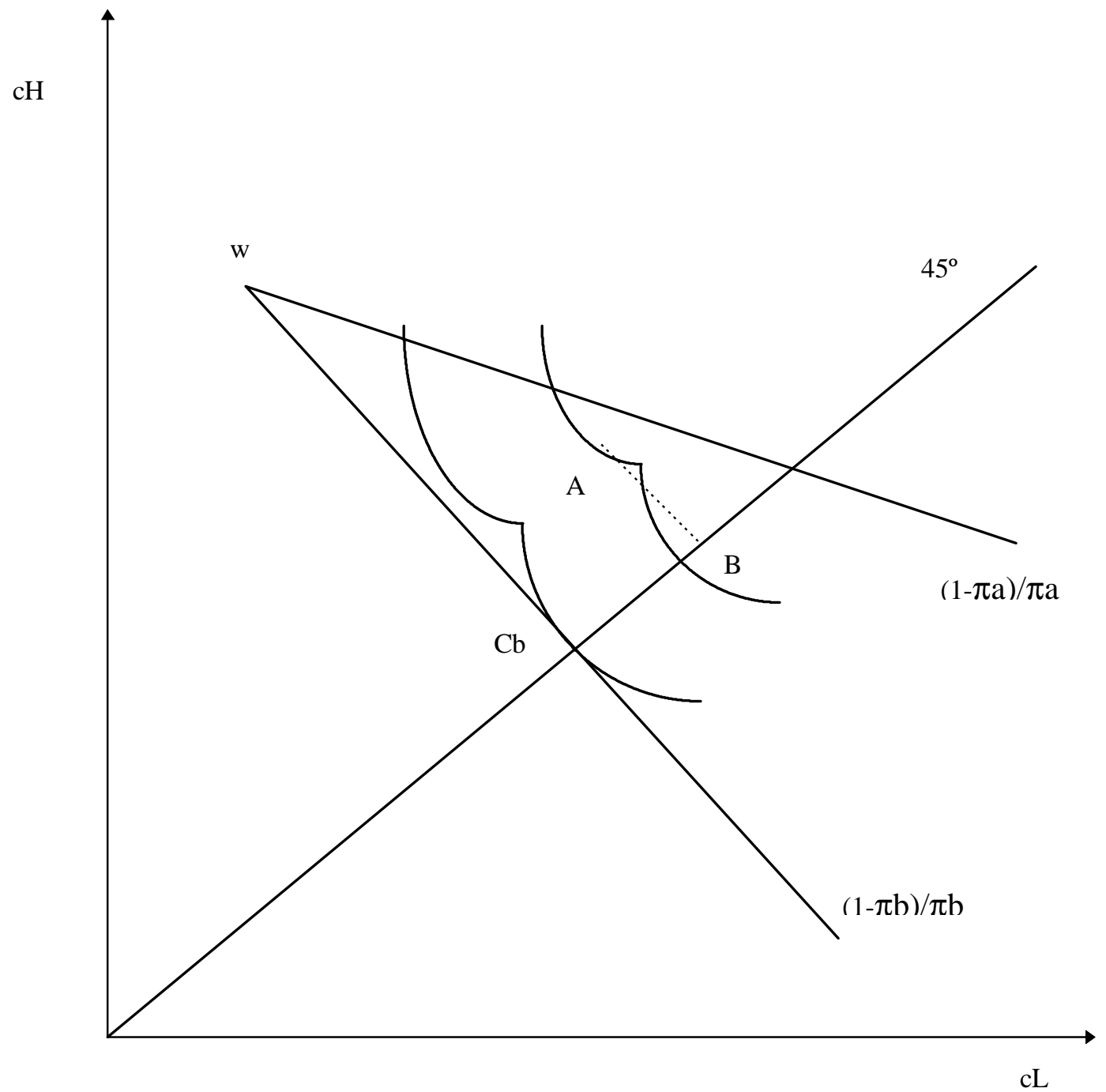


FIGURE 3

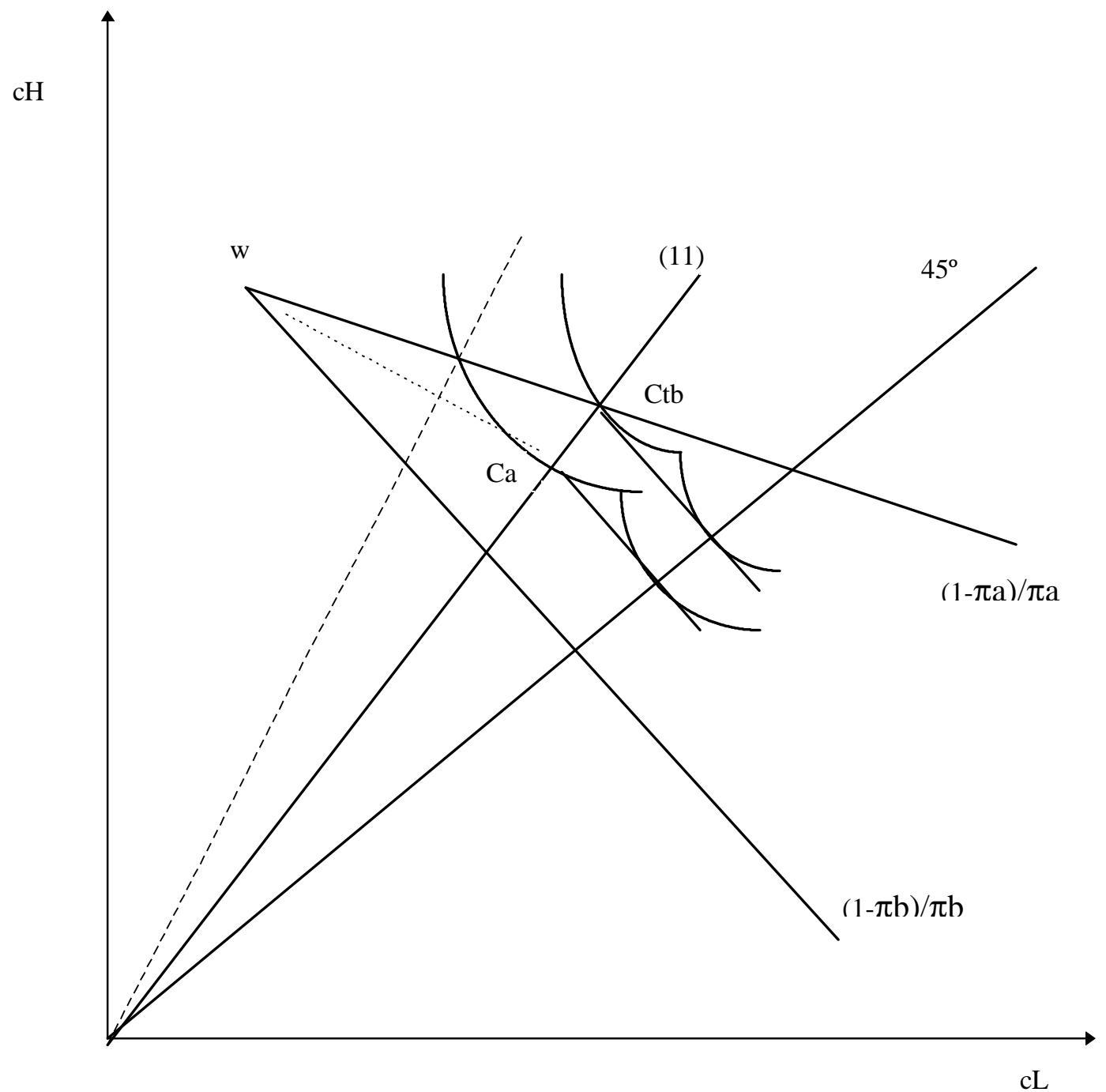

